Acta Cryst. (2002). A58 (Supplement), C160

\section{FORMATION MECHANISM OF SUPERMOLECULAR STRUCTURES} $\mathrm{SiO}_{2}$

\section{Kamashev}

Laboratory of Experimental Mineralogy Institute of Geology Ural Division of Russian Academy of Science 54, Pervamayskaya St. SYKTYVKAR 167982 RUSSIA

In our work we have an attempt to explain formation mechanism of super molecular structures $\mathrm{SiO}_{2}$, according to the data, experimentally received by monodisperse spherical silica particles (MSSP) synthesis. We obtain MSSP by the diameter 235-765 nm using the method [1], which we have enhanced [2]. As a result, in the system the obtained dependences of the diameters of the spherical particles, forming from the concentration of ammonia and water have oscillatory nature. It helps us to suppose the following mechanism of supermolecular crystallization. According to the cluster self-organization ideas of substances at the nano-level [3], received ultra-dispersed silica particles, can be secondary formations. The diameters of the particles (quatarons) depend on solution supersaturation and can reach numerical value about $2.4 \mathrm{~nm}$ in the amorphous state. Correspondingly all compact amorphous formations can be formed as a result of their hierarchical aggregation. Whereas there are no features of crystallinity in the obtained supermolecular structures, it can be supposed that the parent cluster diameter is less than $2.4 \mathrm{~nm}$. It allows us to interpret the received results as the consequence of the hierarchical structure and formation mechanism, which present as a product of the quatarons aggregation - particular forms of the substance cluster self-organization at the nano-level in the supersaturated solutions.

The work was supported by RFFI (grants 00-15-98485, 02-05-64688) and INTAS (project 99-0247).

References

1. W.Stober, A.Fink, E.Bohn, J. Colloid and Interface Sci., 26(1968)62.

2. D.V.Kamashev, A.M.Askhabov, Vestnik Institute of Geology, 12(2000)7.

3. A.M.Askhabov, M.A.Ryazanov, Doklady of Academy of Science, 362(1998)630.

Keywords: SUPERMOLECULAR CRYSTALLIZATION, SPHERICAL PARTICLES OF SILICA, MECHANIZM OF FORMATION

\section{Acta Cryst. (2002). A58 (Supplement), C160 \\ IN-SITU STUDIES ON THE KINETICS AND MECHANISMS OF PHASE TRANSITIONS IN $\mathrm{ZrM}_{2} \mathrm{O}_{8}$ NEGATIVE THERMAL EXPANSION MATERIALS}

J.S.O. Evans S. Allen N. Warmingham

University of Durham Department of Chemistry Science Site, South Road, DURHAM DH1 3LE UK

There has been considerable interest in recent years into the structural properties of the $\mathrm{ZrM}_{2} \mathrm{O}_{8}(\mathrm{M}=\mathrm{W}$, Mo) family of materials which show negative thermal expansion over a wide temperature range. $\mathrm{ZrW}_{2} \mathrm{O}_{8}$, for example, contracts isotropically between $2 \mathrm{~K}$ and $1000 \mathrm{~K}$ and has a coefficient of thermal expansion of $-9 \times 10^{-6}$ between 0 and $350 \mathrm{~K}$. These materials also display an unusual order-disorder phase transition in which one oxygen atom in the structure becomes dynamically disordered above the alpha-beta phase transition. In $\mathrm{ZrWMoO}_{8}$ this oxygen migration occurs from temperatures as low as $200 \mathrm{~K}$. In this contribution we will describe rapid time-resolved powder $\mathrm{X}$-ray and neutron diffraction experiments aimed at probing the kinetics of oxygen migration in these materials as a function of temperature. We will also describe variable temperature experiments that provide key insight into the structural changes that occur as these materials are synthesized from precursor phases. These studies shed considerable light on the synthetic methodologies that allow these metastable materials to be prepared under low temperature conditions, and provide unique information on the mechanism of these processes.

Keywords: NEGATIVE THERMAL EXPANSION OXIDE MIGRATION IN SITU
Acta Cryst. (2002). A58 (Supplement), C160

THE STRUCTURE OF VANADIUM OXIDE NANOTUBES

F. Krumeich M. Woerle F. Bieri H.-J. Muhr R. Nesper

ETH Zuerich Laboratory of Inorganic Chemistry Hoenggerberg HCI-G105 ZUERICH CH-8093 SWITZERLAND

The TEM characterization of vanadium oxide nanotubes has revealed that the tube walls consist of bent vanadate layers between which amine or diamine molecules are embedded [1]. Remarkably, the diffraction patterns of all variants are similar: some reflections correspond to the inter-layer distance, which is determined by the length of the amine molecule, whereas others indicate a square lattice inside the vanadate layers. Thus, X-ray as well as electron diffraction patterns can be explained by a cell with tetragonal metric. Because of the absence of three-dimensional periodicity in tubular materials, it is more appropriate to discuss a tube wall structure in respect of related crystalline compounds. A new triclinic vanadate containing ethylenediamine has been prepared on a route similar to that leading to the nanotubes. The structure, which has been solved from single crystal X-ray data, is composed of ethylenediamine and vanadate layers. In the vanadate layer, square pyramids and tetrahedra are arranged in the same way as in the structure of a barium vanadate [2]. All available experimental findings confirm that this vanadate layer is the basic structural element of the nanotube walls as well [3].

References

[1] F. Krumeich, H.-J. Muhr, M. Niederberger, F. Bieri, B. Schnyder, R. Nesper, J. Am. Chem. Soc. 121 (1999) 8324.

[2] X. Wang, L. Liu, R. Bontchev, and A. J. Jacobson, Chem. Commun. (1998) 1009. [3] M. Wörle, J. de Onate, H.-J. Muhr, F. Bieri, R. Nesper, Chimia 53 (1999) 336.

Keywords: NANOTUBES VANADIUM OXIDE WALL STRUCTURE

Acta Cryst. (2002). A58 (Supplement), C160

\section{X-RAY AND NEUTRON SCATTERING INVESTIGATIONS ON AMORPHOUS PRECURSOR DERIVED Si-C-N AND Si-B-C-N CERAMICS}

J. Haug P. Lamparter M. Weinmann F. Aldinger

Max Planck Institute for Metals Research Heisenbergstrasse 3 STUTTGART 70569 GERMANY

The atomic short-range order of various amorphous $\mathrm{Si}-\mathrm{C}-\mathrm{N}$ and $\mathrm{Si}-\mathrm{B}-\mathrm{C}-\mathrm{N}$ ceramics was investigated by $\mathrm{X}$-ray and neutron scattering. It was found that the structure factors of Si-C-N ceramics of various chemical compositions could be considered as weighted averages of the structure factors of amorphous carbon and amorphous silicon nitride. Thus, the amorphous Si-C-N ceramics consist of an amorphous, graphite-like phase and of amorphous silicon nitride. The partial structure factors of the amorphous carbon phase in Si-C-N ceramics, obtained by the so-called concentration contrast variation method, were simulated with a structure model for amorphous carbon. The simulation reveals that the atomic arrangement in the graphite-like phase agrees with the corresponding arrangement in amorphous carbon with respect to directions in individual layers of atoms, but the order between the layers is much less developed. Detailed investigations of the pair correlation functions of Si-B-C$\mathrm{N}$ ceramics reveal that $\mathrm{B}-\mathrm{N}$ bonds exist and that the Si-B-C-N ceramics consist of an amorphous, $\mathrm{Si}_{3} \mathrm{~N}_{4}$-like phase and an amorphous phase composed of boron, nitrogen and carbon. The correlation range of the B-N bonds was found to be less than the correlation range of the $\mathrm{C}-\mathrm{C}$ bonds. The phase separation in these ceramics occurs at higher temperatures as compared to the $\mathrm{Si}-\mathrm{C}-\mathrm{N}$ ceramics and a high temperature stability up to $2000^{\circ} \mathrm{C}$ is observed. Results from small angle scattering investigations confirm the separation in two amorphous phases. The coarsening of these phases in Si-B-C-N ceramics occurs at temperatures which are $200 \mathrm{~K}$ to $300 \mathrm{~K}$ higher than those for Si-C-N ceramics.

Keywords: AMORPHOUS CERAMICS, X-RAY AND NEUTRON SCATTERING, PHASE SEPARATION 